\title{
Are oral health and dentistry compatible?
}

\author{
Stephen Hancocks OBE
}

Regular readers will be familiar with my predilection for the deliciousness of the English language and the occasional lapse into terrible puns. So you might forgive me if I recall a saying which always puzzled me as a child, 'if smoking is so bad for you, how is it that it cures bacon?' Well, yes, you were warned. The deviousness of the word play, the scripted sleight of hand, is the double meaning of cures and the deflection from the fact that the bacon is already dead, it simply cannot be cured in the sense in which it is implied.

There were however other conundrums that puzzled me as a young man, especially at the time I was thinking about choosing dentistry as a career. School friends, somewhat baffled by my selection anyway, asked why I wanted to take up a profession that was self-defeating. If it was about prevention then the more successful one was the less work there would be to do.

The basis of this was brought back into sharp relief last month when I read an editorial in The Lancet about oral health and prevention. ${ }^{1}$ As a highly respected medical journal The Lancet doesn't much mince its words so when it opined that 'Dentists have also taken little interest in oral health, preferring to treat rather than prevent oral diseases', I have to admit that I sat up straight and took more notice. How dare these medics judge us in this way? The subject of the piece was based on oral health in a global sense rather than specifically here in the UK but it did make me wonder all over again about what must be regarded, particularly to non-dentists, as a central dilemma of our professional role and therefore our daily lives and lifelong work philosophy.

\section{WHAT IF CLASS IS CEASE TO EXIST?}

In fairness, how much of our work, of the business of dentistry, actually exists when you strip out the treatment, the curative element? Let's also think of it another way, something with which we are all familiar, that dentistry begets dentistry. The classic journey of a tooth from a class I cavity and restoration, through to a larger class I, then a class II with a mesial box, then with a distal box, an amalgam core, a root treatment perhaps, a crown, maybe an extraction, and then an implant, another crown...and all from a simple class I. But what if class Is cease to exist? As the children in the fluoride toothpaste generation, born from the 1970s onwards, are now reaching adulthood and soon to be approaching middle age there are far fewer restorations to beget further operative dentistry. As an added irony the prevention that caused this was not even of dentists' making, it was the commercial companies that manufactured the pastes.

\section{NOT THE WHOLE STORY}

I know that that is not the whole story, there is the not so small matter of periodontal disease to cope with. But the treatment of that is far less to do with technical, surgical wizardry than is the case with caries and other team members can be trained, indeed already are trained, to deal with such conditions. Then there is orthodontics, cosmetics and aesthetics, dentures still to be constructed, plenty still to do but, probably, not as much as in the past. It seems to me that in the not too distant future we are going to have to face the fact that as individual practitioners, offering services to individual patients the amount of treatment required will be diminishing. The range of treatment that can be done by others will be increasing and, to cap it all, the ramped-up numbers of new graduates created by the investments made in dental schools by the present government will place hundreds, thousands more colleagues into the market place.

So, the central riddle remains, can you run a business on prevention alone? Or perhaps the question should be can 30,000 plus individuals run businesses on prevention alone in a westernised country with an increasing workforce and a decreasing problem?

Perhaps as a last word we should return to the bacon for inspiration or maybe to the surgeon, what was that other famous proverb 'physician heal thyself'? Or should that be transmuted into '(dental) surgeon cure thyself'? Keep a look out for the smoke.

1. Oral health: prevention is key. Editorial. Lancet 2009; 373 (9657): 1

DOI: $10.1038 /$ sj.bdj.2009.81 